\title{
Business Model Innovation Research in the Theory of $\mathrm{E}=\mathrm{MC}^{2}$
}

\author{
Boyu Chen \\ College of Management and Economics \\ Tianjin University \\ School of Law and Politics \\ Tianjin University of Technology \\ Tianjin China \\ e-mail: egg425@qq.com
}

\author{
Shentong Mo \\ School of Electronic Information Engineering \\ Tianjin University \\ Tianjin China \\ e-mail: moshentong678@126.com
}

\author{
Qiang Zou* \\ College of Management and Economics \\ Tianjin University \\ School of Electronic Information Engineering \\ Tianjin University \\ Tianjin China \\ e-mail: zouqiang@tju.edu.cn \\ * Corresponding Author
}

\begin{abstract}
This paper studies innovative approaches business models based on a large background of innovation and entrepreneurship. In-depth analysis of the public A-space operationsstatus quo, based on the systematic analysis of the iterative innovation method under the pattern of innovation and entrepreneurship, the establishment of open-source platform for innovation and entrepreneurship methods of operation, and to transform the classic formula of Einstein's theory of relativity, the formation of a congregation guidelines create A-space operations, in order to promote innovative methods of work provides guidance ideas.
\end{abstract}

Keywordsmodels;open source;server

\section{BACKGROUND}

On January $28^{\text {th }}, 2015$, Premier Li Keqiang chaired a State Council executive meeting to determine the support for the development of "creating public A-space" of policies and measures for entrepreneurship and innovation to build a new platform. On March $11^{\text {th }}$,the State Council promulgated the "Guiding Opinions on the public development of public A-space to promote innovation and entrepreneurship." To speed up the public A-space which is to be built by 2020 , to form a group to effectively meet the public demands for innovation and entrepreneurship, a strong professional services capabilities was created which contains new business service platform for public space. Develop public A-space is not only to promote the country's needs "public entrepreneurship, peoples' innovative", but also social development.

China has initially formed a passenger space record, entrepreneurship coffee, Innovation Works, National Innovation Demonstration Zone, the national high-tech zones, technology business incubators and other components of innovation and entrepreneurship support system, and has also gradually worked out some practical innovation and entrepreneurship service working methods. However, these methods do not work for innovation or entrepreneurship service system, because it relies on the body's limitations. These methods work only for the public record of a link in the chain or a few areas. The service areas can only cover one or several aspects, which results in public which is a topic not often getting effective service in the whole chain of innovation and entrepreneurial activity, innovation and entrepreneurship indirectly leading to the low success rate, survival rates being low, "three lows" situation of low industrialization.

Therefore, to solve the "three lows" situation, a fundamental way should be applied to establish and diversified the whole chain of innovation and entrepreneurship services working methods. In the early days, to be on the basis of the applicable conditions and characteristics of the original innovation and entrepreneurship analysis method, combining fixed and demand for the service object in the whole chain of innovation and entrepreneurship, implementation of these methods on different spatial and temporal integration, integration concise the old way; then, with the advance of the public record, gradually summed up the success stories from the new approach innovation.

\section{ANALYSIS AND DISCUSSION}

Public A-space is the general term vitality and viability of its development capacity. Public service is not just a place to create space or agency within a certain range, it should be also an open ecosystem of innovation and entrepreneurship. Its main function is to provide services for the needs of innovation and entrepreneurship activities. Currently, the public A-space of the main targets for the entrepreneurial success and business survival, this is only short-term effect evaluation methods evaluation. When evaluating long-term effects, their survival and development capacities should be firstly considered. 
Therefore, the development of public space creates another core issue which is to enhance its vitality.

\section{A. Status and trends in innovative ways}

Innovation means: existing knowledge and material, in particular environment, improve or create new things (including but not limited to, a variety of methods, elements, path, environment, etc.), and to get some beneficial effects of behavior. With the development of innovation theory, innovation model has been developed to the fifth generation [1]. The fifth generation model of innovation A-systems integration and network models. Systems thinking, system concepts, systems approach gradually penetrated into the innovation process. Innovation is also seen as a complex network system, it requires companies to have the innovation in various activities, and enterprises should established close strategic alliance with customers, suppliers, information sources, research institutions. The fifth generation of method model is conceders as the representative for open innovation and public record.

According to Bessant [2] scholars put forward on behalf of ordinary employees as the core of the full innovative ideas, Chesbrough [3] proposed the concept of open innovation, that could replace the traditional closed innovation activities. Von Hipple [4] and others on a series of user innovation research proved from outside the enterprise "non-expert" groups play an increasingly important role in the innovation process. And according to Zhao Fu [5] through out a research on Internet, based on the concept of "public collaborative innovation", pointed out that internal employees, customers, the public are three main body enterprises initiated public collaborative innovation, since they have a non-organization popular features, they are based on collaborative innovation in the Internet platform boundaries are becoming blurred. Song Gang [6] argued that the integration and development of information and communication technology to promote the formation of knowledge society, and fluid properties promote innovative knowledge society democratization. Therefore, borders and border laboratories of innovation activities in the traditional sense is melting. This change brought by the Internet for business use of mass innovation provides an opportunity, in the real world new and innovative practice model has been unprecedented liberation and development.

\section{B. Method of Entrepreneurship Status and Trends}

Entrepreneurship is the entrepreneur who can have the resources to optimize integration to resources or through their own efforts, thereby creating a greater economic or social value of the process [7]. Entrepreneurship is a way of working and it is a necessity for entrepreneurs to operate, organize, use ponder service, technology, artifacts job, reasoning and judgment behavior.

The Study of existing entrepreneurship theories are more concentrated in the quality of entrepreneurs, business projects, marketing and business models [8]. Research on entrepreneurial approach also corresponds to the above factors which are mostly carried out. But in the actual process, in many cases, innovation can promote entrepreneurship, namely innovative entrepreneurship.

Innovative entrepreneurship [9] refers to the entrepreneurs to establish new markets and customer base, breaking the traditional philosophy, guided by its own creative activity and the formation of new markets, by fostering the market to create opportunities, and continuously meet the customer's existing demands and the development of its potential demands.In addition,gradually establish customers' loyalty and reliance on enterprise comprehensive economic and social progress provide great motive force of a class of business model. Innovative startups to meet customers' needs and open up the primary task of socio-economic development since employment has great leading role. While innovative entrepreneurship fewer cases, in which Haier open innovation platform and business history United Technologies Research Center, but such cases usually become a classic, the optimal representation.

Haier Open Innovation Platform [10] (Haier Open Partnership Ecosystem, called HOPE), by the Haier Open Innovation Center to develop and operate to build the world's largest innovation ecosystems and the whole process of interactive innovation community, serving all global innovators. Follow platform openness, cooperation, innovation, sharing of ideas, through the integration of world-class resources, intelligence and outstanding creative collaboration with global research and development institutions and individuals to provide cutting-edge technology as a platform for user information and the value of innovative solutions. Ultimately maximize the interests of all stakeholders, and make all the resources on the platform and technology providers demand side benefit sharing. The establishment of the innovative platform, did not only greatly reduce the cost of innovation Haier Group, increased innovation and efficiency, and intellectual property rights in the transaction process, but also gained a lot of money for the Group profit.

United Technologies Research Center (UTRC) [11] is directly under the UTC research institutions in a number of important technical areas, world-leading positions. Commercial mode management technology and intellectual property is the originator of open innovation practices. In 2010, United Technologies company turnover more than 50 billion US dollars, with more than 200,000 employees worldwide.

\section{The importance of open innovation}

Open Innovation [12] is the enterprises' reduction of innovation cost, creativity and the role of external market channels of external and internal creativity and rise to internal market channel Closed Innovation under the same important position, balanced and coordinated internal and external innovative resources. Open Innovation is a joint venture by an external, technology licensing, outsourcing research, technology partnerships, strategic alliances or risk investment and some other business models, and services.

The difficulty lies in open innovation management resource aggregation and intellectual property.Open innovation requires the body to effectively integrate innovation, use of corporate external resources capability, including customer requirements for good corporate governance, including all resource providers. Meanwhile, in order to improve the innovation efficiency, require companies to complete the resources gathered in the whole 
chain and at the same time each link in the innovation chain in different roles [13].

Outside the enterprise, there is a lot of knowledge and technology resources, so companies must become active buyers of intellectual property rights (for external resources in terms of knowledge and technology) and seller (in terms of internal resources, knowledge and technology). [14] Management of intellectual property is not only to achieve the purpose of promoting the development of their own business, but also from others trying to benefit from the use of intellectual property.[15] The perfect technology, economic legislation, in particular the protection of intellectual property legislation, they are both to protect the legitimate rights and interests of participants in open innovation, but also an effective way to protect and obligations of technology diffusion, transfer and conversion, and can also be effective oversight, sanctions violate the legal rights and interests. [16] It shall establish its own intellectual property management agency.

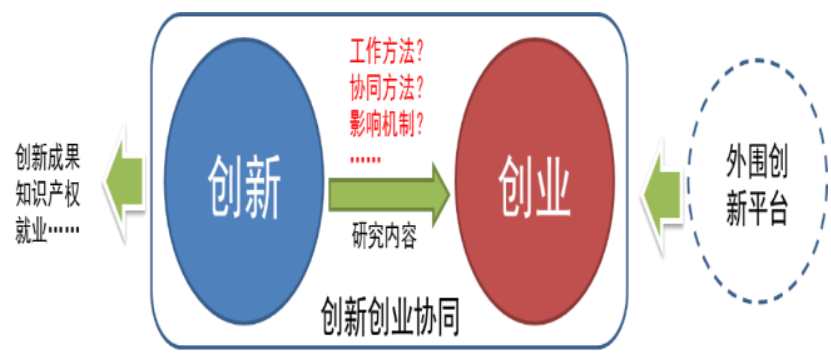

Figure 1. innovation and entrepreneurship research collaboration mechanism

The results of flowing law, technology, personnel, finance and other researches between innovation and entrepreneurship, and their relationship with other interrelated topics of innovation and entrepreneurship. Most of today's public A-space only considers innovation to the risks and rates of return success rate of entrepreneurship and financial investment. [17]But the real guiding policy should be innovation - the pattern of collaborative innovation entrepreneurship. In the original innovation venture platform, it should be output from the success of the enterprise that is the failure of the enterprise, into a successful business incubation, intellectual property rights transfer of institutions and vocational skills training, entrepreneurship depth people. [19]At the same time, the platform should be open source, open mode, allowing start-ups and innovative platforms and other peripheral filtered into the pre-incubation process to complete this platform, enabling open source management innovation platform.

\section{The importance of innovation imitation}

Creative imitation by Levitt of Harvard Business School, first proposed, Drucker put it as a kind of successful entrepreneur strategies. Imitation of the original is not creative, creative imitation means creative in the application. Creative imitator is not a product or a service innovation, it just perfects the product or service, and to reposition it, for example modifying the outstanding products' characteristics, in order to slightly adapt to different markets. Thus in a short time, the new things will truly meet the needs of customers, which might lead to dominate the market. So for now this is a business model innovation iterative pattern, the means of mathematical models and the laws of the guide should be taken in order to maximize performance.

\section{FORMULA AND ANALYSIS}

$\mathrm{E}=\mathrm{MC}{ }^{2}$ Einstein's theory of relativity of such a formula, originally describe the quality of the object will reach the speed of light into energy when in motion speed, so in accordance with the laws of linear motion, limit the speed of movement of objects on earth is the speed of light $\mathrm{C}$, otherwise, it will be converted into mass energy $\mathrm{M} \mathrm{E}$, thereby disappear.

Here, this formula infrastructure is used as a new management model in order to put forward new innovative approaches to theoretical formula:

$$
\mathrm{E}=\mathrm{M} \mathrm{C}^{2}
$$

$\mathrm{E}=$ Economy (economic value), $\mathrm{M}=$ Model (innovative business models to achieve high conversion rate), $\mathrm{C}=$ Customer (mass customer, namely massive resources form huge success stories)

Where the parameter $\mathrm{C}$ (customer) including a massive hit off, massive expert, massive financial investors and massive enterprise; $M$ (model) is marked innovative business models, such as the public unified Aspace server (in order to achieve with a group of experts to serve all public A-space, a substantial cost savings, improve the credibility Platform Alliance), the classification of the massive project library system services (Genesis passenger self-sustaining project team, experts will conduct screening and counseling; expert argued that experts self-sustaining projects shares and become a shareholder of its expert consultants), dedicated to the service orientation mode (Union public A-space, hatch their respective classification category of good projects, to maximize the effectiveness and reduce competing alliance platform space, forming a platform economy).

At the same time, it can be seen that the heavy weight parameter $\mathrm{C}$ is $\mathrm{C}^{2}$, vital resource platform is more visible massive record passenger, the mass of the experts, the mass of financial investors, massive enterprises.[20]

\section{CONCLUSIONS}

For now the public A-space, the overall operation of the key highlights that: (1) the mass of good projects and (2) a high conversion rate. In this context, innovative mimic Einstein's theory of relativity formula $\mathrm{E}=\mathrm{M} \mathrm{C}{ }^{2}$, clear analysis of the innovation and entrepreneurship of the public record of space operations methods, the study of innovation and entrepreneurship system provide a theoretical formula.

\section{References}

[1] OTTAVIANO G I P, THISSE J F. Integration, agglomeration and the political economics of factor mobility [J], Journal of Public Economics, 2002, 83(3), 429-456.

[2] MELITZ M J, OTTAVIANO G I P, Market size, trade, and productivity[J], Review of Economic Studies, 2008, 75(1), 295-316. 
[3] SYVERSON C, Market structure and productivity: a concrete example[J], Journal of Political Economy, 2004, 112(6), 11811222.

[4] RICHEY T, Problem structuring using computer-aided morphological analysis[J], Journal of the Operational Research Society, 2006, 3(57), 792-801.

[5] Teece,D.J, Business Models, Business Strategy and Innovation [J], Long Range Planning, 2010, 43, 2-3.

[6] OLIVER G, ENKEL E, Towards a Theory of Open Innovation: Three Core Process Archetypes[J], R \&D Management, 2004, 1, 118.

[7] WEST J, GALLAGHER S, Challenges of Open Innovation:The Paradox of Firm Investment in Open Source Software[J], R\&D Management, 2006, 36 (3) , 315-328.

[8] CHESBROUGH H, Open Innovation:Researching a New Paradigm[M], Oxford University Press, 2006, 109-133.

[9] CHESBROUGH H, GE' s Ecomagination Challenge: An Experiment in Open Innovation $[\mathrm{J}]$, California Management Review, Spring, 2012, 54(3),140-154.

[10] Stratton R, Mann D, Systematic innovation and the underlying principles behind TRIZ and TOC [J], Journal of Materials Processing Technology, 2003(139), 120-126.

[11] Terninko J, The QFD, TRIZ and Taguchi connection: customerdriven robust innovation[C], The Ninth Symposium on Quality Function Deployment, Novi, 1997, 374-380.
[12] Sawaguchi M. Effective approaches to solving technical problems by combining TRIZ with VE [C], The proceedings of Altshuller Institute TRIZCON2000, 2000, 119-126.

[13] Kortuem - G, Kawsar F, Fitton - D, et al, Smart objects as building blocks for the Internet of things[J], Internet Computing, IEEE, 2010, 14(1), 44-51.

[14] Kranz · M, Holleis · P, Schmidt · A, Embedded Interaction:Interacting with the Internet of Things[C], Internet Computing, IEEE, 2010, 14(2), 46-53.

[15] Welbourne E, Battle $\cdot$ L,Cole $\cdot G$, et al, Building the Internet of Things Using RFID:The RFID Ecosystem Experience[C], Internet Computing, IEEE, 2009, 13(3), 48-55.

[16] Broll· G, Rukzio E, Paolucci- M, et al, Perci: Pervasive Service Interaction with the Internet of Things[C], Internet Computing, IEEE, 2009, 13(6), 74-81.

[17] Giner-P, Cetina $\mathrm{C}$, Fons- J, et al, Developing Mobile Business Processes for the Internet of Things[C], Pervasive Computing, IEEE, 2010, 9(2), 18-26.

[18] Rolf H.Wber, Internet of Things-New security and privacy challenges[J], Computer Law \& Security Review, 2010, 26(1), 2330 .

[19] Dimitris· Kiritsis, Closed-loop PLM for intelligent products in the era of the internet of things[M], Computer-Aided Design, Corrected Proof, 2010, 23-25.

[20] Rappa, Michael,The Utility Business Model and the Future of Computing Services[J], IBM Systems Journal, 2004, 1, 34-39. 